\title{
EARLY STUDY: THE EFFECT OF TAURINE ON GROWTH OF GOURAMI (Osprhonemus goramy) AND TILAPIA (Oreochromis niloticus) JUVENILES
}

\author{
Endang Linirin Widiastuti, M.Kanedi, Nuning Nurcahyani \\ Biology Dept - Faculty of Math \& Sciences University of Lampung \\ JI. Prof. DR. Sumantribrojonegoro No. 1 - Bandar Lampung -Lampung 35145 \\ Email: elwidi@yahoo.com/
}

\begin{abstract}
Taurine in diet affected increasing in body weight and length as well as survival rate of juveniles or adults of many marine fishes. It is explained that taurine presumably increased in their ability to tolerate the hypertonicity of seawater as well as to improve their metabolism which leaded to induce maturation. In order to elucidate the effect of taurine physiological universally in the fishes, early study was conducted on freshwater fishes namely gourami (Osprhonemus goramy) and tilapia (Oreochromis niloticus). The growth was determined by their body weight and morphological changes included the length and width of their body. The reproductive status was determined by measuring fish gonadosomatic indexes (GSI) (only for tilapias). Eight experimental groups were chosen consisted of two groups with commercial fish food with and without taurine and two groups with natural fish food (consisted of $50 \%$ Xanthosoma sagittifolium) with and without taurine. Amount of taurine given was $0.4 \mathrm{mg} / \mathrm{fish} /$ day. Complete randomized design with factorial $2 \times 2$ was applied to this study with 40 gourami juveniles (@7 grams in weight) and 40 tilapias (@ 50 grams in weight) were used for the experimental units. The study was conducted in 2 months. Analysis variances and LSD and/or t-test at $5 \%$ were used to determine the differences among experimental groups. The results indicated that taurine groups increased their body weight for $25-66 \%$ compared to the control (no taurine) as well as their body length and width $(p \leq 0.05)$. Yet, the GSI of tilapias was not shown any significantly different. In this early study we indicated that taurine affected the growth in juvenile gourami and tilapia. However, further experiments related with physiological changes and reproductive status was still needed to complete the study.
\end{abstract}

Key words: Taurine, gourami, tilapia, growth rate

\section{INTRODUCTION}

Taurine is amino acid derivative and in form of very simple compound, thus it is assumed it can be transported easily in the animal tissues. Previous study indicated that taurine or/without inositol increased the survival rate of Epinephelus fuscoguttatus, Forskal or grouper juveniles (Widiastuti, et al2005) or even sea bream juveniles. Beside that taurine also indicated its effect on Rachycentron canadum, cobia's growth rate as well elevated maturation of the premature female cobia (Widiastiuti, et al2011).

As one of many marine fishes, the growth of larvae of cobia (Rachycentron canadum), as well as others marine fish larvae in general, depend on the ability of the larvae to deal with the common hypertonicity stresses occurred in the seawater during their development reaching up to juvenile. The study indicated that ability of the cobia larvae to coup with this stress could be improved by giving supplement on their diets such as with mannan oligosaccharide (MOS) (Salze, et al., 2008). It was assumed that this MOS affected on the development of the intestinal villi of cobia, as a result, this well development of villi increased the food absorption which necessary for their development. Increase in development and efficiency on food and consumption rate of red sea bream (Pagrus major) juvenile also affected by added some supplement in their diets (Matsunari, et al, 2008).

ISSN 2413-0877 @ 2015 The Authors.

Published by KnowledgeE Publishing Services This is an open access article under the CC BY-NC-ND license (http://creativecommons.org/licenses/by-nc-nd/4.0)

Selection and Peer-review under responsibility of the 3rd ICBS-2013

Doi http://dx.doi.org/10.18502/kls.v2i1.169 
Based on previous study of the taurine effects on marine fishes, it is expected that taurine also affect in similar way on the freshwater fishes juvenile, especially for their growth rate and development, even though the common environmental stress might not similar. Therefore, early study on the effect of taurine as supplement on fish diet would be applied to the freshwater fishes and growth rates as well as reproductive development were determined in order to generalize the effect of taurine on fishes, either marine or fresh water fishes. In this early study, gourami (Osprhonemus goramy) and tilapia (Oreochromis niloticus) were chosen to represent the freshwater fishes.

\section{MATERIALS AND METHODS}

Forty juveniles of gourami (Osprhonemus goramy) and tilapia (Oreochromis niloticus) collected from hatchery/supplier in eastern part of Lampung Province were used for experimental units. The body weight of gourami was approximately 7 grams and tilapia was 50 grams. They were kept in aerated aquarium (fish tanks) and acclimated in laboratory condition with constant water temperature $\left(26-27^{\circ} \mathrm{C}\right)$ and constant $\mathrm{pH}(7-8)$ for a week prior experimental study. They were grouped into eight different groups. Each of groups contained of 5 fishes and used for replication and received different treatments of food (commercial and natural food consisted of 50\% Xanthosoma sagittifolium) and with/without taurine ( 0 and $0.4 \mathrm{mg} / \mathrm{ind} /$ day). Taurine used was commercial dietary taurine. Water temperature and $\mathrm{pH}$ were maintained constantly throughout the study.

Morphological changes such as the body weight, length and width (which measured surrounding their stomach area) were determined. Complete randomized design with factorial 2x2 was applied to this study for both species of gourami and tilapia. Data collected for body weight, length and width was the differences values from $t_{n}-t_{0}$ and was analyzed by ANOVA to determine any differences among experimental groups. The Least Significant Difference (LSD) and/or t-test at $5 \%$ was used to determine the differences among experimental groups. This early study was conducted in 2 months.

\section{Morphological samples}

Quick measurement of the morphological changes was made for every fish as experimental units. The animals were weighted to the nearest $0.01 \mathrm{~g}$, and were measured in the length and width to the nearest $1 \mathrm{~mm}$.

\section{Gonadosomatic Index}

Gonadosomatic index (GSI) of the animal samples were calculated by using formula of:

$\mathrm{GSI}=[\mathrm{GW} /(\mathrm{TW}-\mathrm{GW}) \mathrm{X} 100] \quad$ (Brown-Peterson, et al, 2001)

GW : gonad weight, TW : total body weight

Gonadosdomatic index only applied for tilapia, but not for gourami.

\section{Special Growth Rate (SGR)}

In order to comprehend the effect taurine on fish diet, special growth rate of tilapia juveniles was determined by applying the formula as below:

$S G R=(\operatorname{Ln~WT}-\operatorname{Ln} W 0) / t \times 100 \%$ 
In which: WT was body weight at $\mathrm{t}$-day, $\mathrm{W} 0$ was body weight at $\mathrm{t}=0$, and $\mathrm{t}=$ day observation

\section{RESULTS AND DISCUSSION}

Both taurine treatment groups $(0.4 \mathrm{mg} / \mathrm{ind} /$ day $)$ for both species fishes were fed with natural or commercial fish food showed significantly increase in body weight compared to the control groups $(0.0 \mathrm{mg} / \mathrm{ind} / \mathrm{day})$ for about $33 \%$ - $66 \%$ (Table 1$)(p \leq 0.05)$ for gourami and $50-200 \%$ for tilapia. The body length if fish also indicated the difference between control and treatment groups. On the other hand, the body width of gourami of treatment group did not show any significantly differences (Table 2).

Table 1. Taurine effect on body weight of gourami (Osprhonemus goramy) and tilapia (Oreochromis niloticus)

\begin{tabular}{ccccccc}
\hline Day & \multicolumn{3}{c}{ Gourami $(\mathrm{X} \pm$ SEM) gram } & \multicolumn{3}{c}{ Tilapia $(\mathrm{X} \pm$ SEM) gram } \\
\cline { 2 - 6 } observed & $\mathrm{A}$ & $\mathrm{B}$ & $\mathrm{C}$ & $\mathrm{D}$ & $\mathrm{A}$ & $\mathrm{B}$ \\
\hline $10^{\text {th }}$ & $0.66 \pm 0.06$ & $0.72 \pm 0.10$ & $0.70 \pm 0.32$ & $0.71 \pm 0.17$ & $0.11 \pm 0.02$ & $0.36 \pm 0.03^{* *}$ \\
$20^{\text {th }}$ & $1.52 \pm 0.25$ & $1.80 \pm 0.12$ & $1.40 \pm 0.31$ & $1.69 \pm 0.27$ & $0.34 \pm 0.07$ & $0.85 \pm 0.04^{\star *}$ \\
$30^{\text {th }}$ & $2.44 \pm 0.21^{\mathrm{b}}$ & $4.02 \pm 0.21^{\mathrm{a}}$ & $1.96 \pm 0.45^{\mathrm{b}}$ & $2.97 \pm 0.52^{\mathrm{ab}}$ & $1.15 \pm 0.04$ & $1.94 \pm 0.08^{* *}$ \\
$40^{\text {th }}$ & $2.72 \pm 0.27^{\mathrm{b}}$ & $4.52 \pm 0.91^{\mathrm{a}}$ & $2.96 \pm 0.28^{\mathrm{b}}$ & $3.77 \pm 0.69^{\mathrm{ab}}$ & $1.94 \pm 0.06$ & $2.90 \pm 0.08^{* *}$ \\
\hline
\end{tabular}

A: commercial fish food without taurine; B: commercial fish food with taurine $(0.4 \mathrm{mg} /$ fish/day)

C: natural fish food without taurine; D: natural fish food with taurine $(0.4 \mathrm{mg} / \mathrm{fish} / \mathrm{day})$

a/b significant at $p<0.05,{ }^{*}$ * t-test at $p<0.01$

Table 2. Taurine effect on morphological changes of gourami (Osprhonemus goramy)

\begin{tabular}{|c|c|c|c|c|c|c|c|c|}
\hline \multirow{3}{*}{$\begin{array}{c}\text { Day } \\
\text { observed }\end{array}$} & \multicolumn{8}{|c|}{ Gourami $(X \pm$ SEM) cm } \\
\hline & \multicolumn{4}{|c|}{ Body Width } & \multicolumn{4}{|c|}{ Body Length } \\
\hline & A & $B$ & $C$ & $\mathrm{D}$ & $A$ & $B$ & $C$ & $\mathrm{D}$ \\
\hline $10^{\text {th }}$ & $0.16 \pm 0.14$ & $0.30 \pm 0.15$ & $0.34 \pm 0.14$ & $0.60 \pm 0.09$ & $0.16+0.14$ & $0.30+0.15$ & $0.46+0.17$ & $0.40+0.08$ \\
\hline $20^{\text {th }}$ & $0.36 \pm 0.24$ & $0.50 \pm 0.13$ & $0.64 \pm 0.09$ & $1.28 \pm 0.20$ & $0.36+0.24$ & $0.50+0.13$ & $0.58+0.12$ & $0.70+0.17$ \\
\hline $30^{\text {th }}$ & $0.48 \pm 0.18$ & $0.68 \pm 0.18$ & $1.00 \pm 0.11$ & $2.00 \pm 0.15$ & $0.48+0.23$ & $0.68+0.18$ & $0.72+0.17$ & $0.94+0.23$ \\
\hline $40^{\text {th }}$ & $0.58 \pm 0.24$ & $0.82 \pm 0.19$ & $1.26 \pm 0.18$ & $2.70 \pm 0.38$ & $0.58+0.24$ & $0.82+0.19$ & $1.18+0.19$ & $1.14+0.21$ \\
\hline
\end{tabular}

A: commercial fish food without taurine; B: commercial fish food with taurine $(0.4 \mathrm{mg} /$ fish/day)

C: natural fish food without taurine; D: natural fish food with taurine $(0.4 \mathrm{mg} / \mathrm{fish} /$ day $)$

While in tilapia, the increase in body weight was parallel with both increase in body length and width (Table $3, p<0.01$ ). Overall, this indicated that taurine in the diet could affect the gaurami and tilapia growth.

Table 3. Taurine effect on morphological changes of tilapia (Oreochromis niloticus)

\begin{tabular}{|c|c|c|c|c|}
\hline \multirow{3}{*}{$\begin{array}{l}\text { Day observed } \\
(n)\end{array}$} & \multicolumn{4}{|c|}{ Tilapia (X+ SEM) cm } \\
\hline & \multicolumn{2}{|c|}{ Body Length } & \multicolumn{2}{|c|}{ Body Width } \\
\hline & $A$ & $B$ & A & $B$ \\
\hline $10^{\text {th }}(10)$ & $0.16 \pm 0.02$ & $0.39 \pm 0.04^{* *}$ & $0.13 \pm 0.02$ & $0.25 \pm 0.04^{* *}$ \\
\hline $20^{\text {th }}(10)$ & $0.54 \pm 0.04$ & $1.05 \pm 0.06^{* *}$ & $0.29 \pm 0.04$ & $0.50 \pm 0.04^{* *}$ \\
\hline $30^{\text {th }}(10)$ & $0.98 \pm 0.03$ & $1.74 \pm 0.07^{* *}$ & $0.52 \pm 0.07$ & $0.83 \pm 0.03^{* *}$ \\
\hline $40^{\text {th }}(10)$ & $1.35 \pm 0.11$ & $1.94 \pm 0.07^{* *}$ & $0.76 \pm 0.05$ & $1.30 \pm 0.04^{* *}$ \\
\hline
\end{tabular}

In order to determine the specific growth rates (SGR) of these two species fresh water fishes, their increase in body weight was calculated per 10 days and can be seen in Figure 1. 


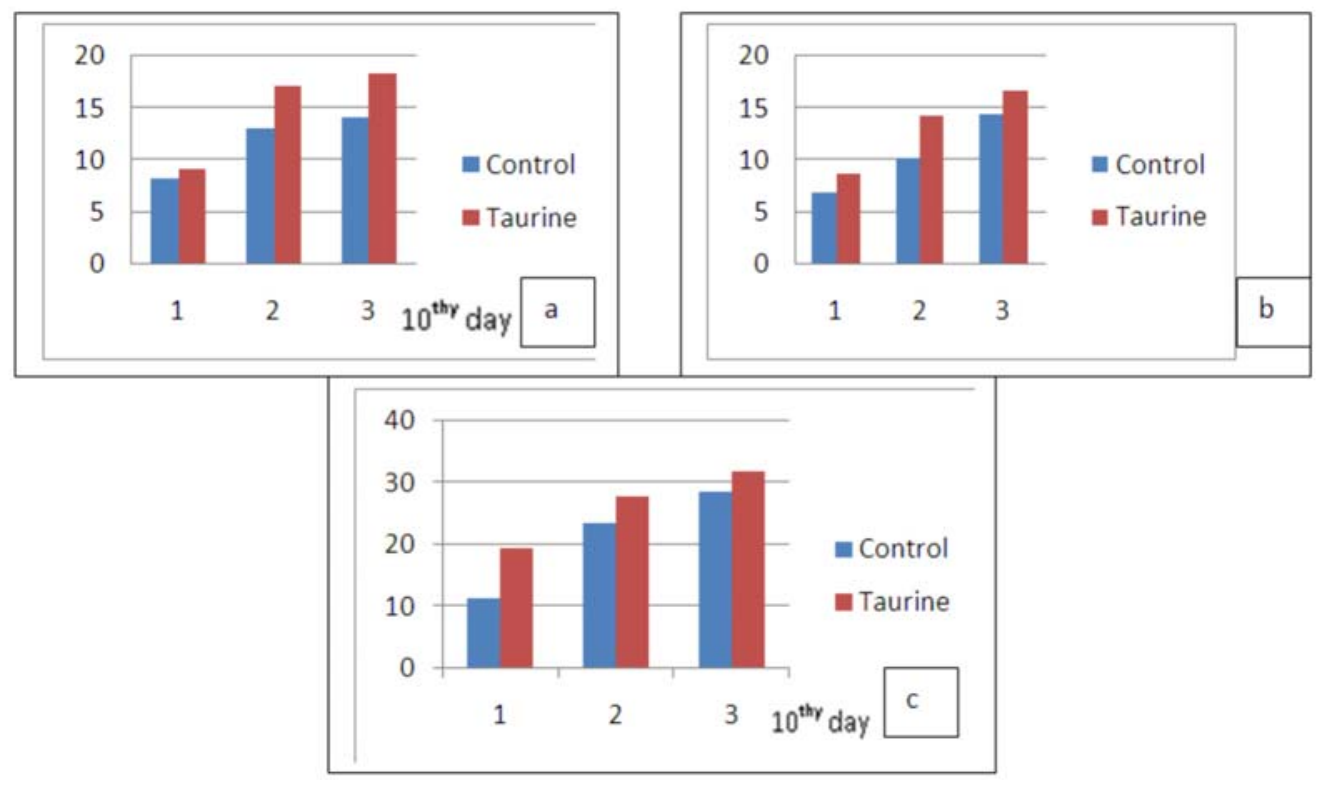

Figure 1. Effect of taurine supplement on the specific growth rate (SGR) of gourami with commercial food (a), natural food (b) and tilapia with natural food (c) $(n=10)$, the $x$ axis was the length of time observation was made in every $10^{\text {th }}$ day

The SGR of both fresh water fishes were influenced by giving taurine in their diets. It was stated that Taurine has high effect on mammalian metabolism, and found either in the skeletal muscle or in the cardiac muscle (Bakker \& Berg, 2002; Goodman et al., 2009). Beside that Taurine also had an effect on the kidney (Mozaffari \& Schaffer, 2001), eyes (Militante and Lombardini, 2002; El-Sherbeny, et al, 2004), as well as the brain (Gelder, 2005; Schurr, et al 1987), even in white blood cell (leukocyte) function (Wang, et al, 2009). In non mammalian, taurine also had effect on cobia and groupers (Widiastuti, et al, 2005). Since taurine also affected on growth rate of fresh water fishes in this study, therefore, we assumed that the taurine affected fresh water fishes juveniles for their muscle growth by improving the ability to absorb nutrient in the villi. Improving the juvenile metabolism also was expected from taurine uptake since taurine had an insulin-like action, it could modulate the insulin work (Baianchi, et al, 2006), presumably taurine improve the efficiency of food intake. This insulin-like modulation then might affect on converting nutrient into developing new tissues or depositing nutrient in the tissues just like those of adipose tissues formation of juvenile fresh water fishes. In order to understand this efficiency in food intake, we measure the food conversion rate of each groups of tilapia. The result indicated that groups without taurine as supplement on their diet was double compared to those had taurine on their diet (data was not shown).

Table 4. Effect of taurine on body weight of premature tilapia (Oreochromis niloticus)

\begin{tabular}{ccc}
\hline Day observed & \multicolumn{2}{c}{ Tilapia $(X \pm$ SEM) gram } \\
\cline { 2 - 3 } & \multicolumn{1}{c}{$\mathrm{A}$} & $\mathrm{B}$ \\
\hline $10^{\text {th }}$ & $2.22 \pm 0.37$ & $5.21 \pm 0.48^{*}$ \\
$20^{\text {th }}$ & $3.21 \pm 0.45$ & $5.92 \pm 0.60^{*}$ \\
$30^{\text {th }}$ & $3.50 \pm 0.56$ & $7.07 \pm 0.69^{*}$ \\
\hline
\end{tabular}

A: commercial fish food without taurine; B: commercial fish food with taurine $(0.4 \mathrm{mg} / \mathrm{fish} /$ day $)$

* t-test at $p<0.05$ 
As it already mentioned before from the previous study that taurine affected on reproductive maturation of premature cobia, we expected that taurine might also affect the development of gonad of fresh water fish, in this case we used tilapia as experimental unit. In this early study we measured the gonadosomatic index of the juvenile tilapia (Table 5). Yet, we only could indicate that there was no different in GSI number between treatment and control groups. One reasonable explanation of this case was that the experimental unit of tilapias might be still in stage of juvenile and the gonad development has not been differentiated. Besides that, the length of time of the study was considered to be very short, only 2 months. It should take more than 6 months.

Table 5. The gonadosomatic index (GSI) of tilapia every 10 days observation

\begin{tabular}{ccc}
\hline \multirow{2}{*}{$10^{\text {th }}$ Day Observation } & \multicolumn{2}{c}{ GSI $(X \pm$ SEM) } \\
\cline { 2 - 3 } & Control (without taurine) & With taurine \\
\hline 0 & $3.67 \pm 1.25$ & $3.99 \pm 1.18$ \\
1 & $4.04 \pm 1.82$ & $4.54 \pm 0.99$ \\
2 & $4.72 \pm 0.89$ & $3.74 \pm 0.98$ \\
3 & $5.51 \pm 1.68$ & $4.59 \pm 0.23$ \\
\hline
\end{tabular}

*Data was shared for student's thesis 2013

We can conclude that taurine on fish diets has an effect on the growth of fresh water fishes, namely gourami (Osprhonemus goramy) and tilapia (Oreochromis niloticus) for 25 - $66 \%$ compared to the control groups. However, this growth might not be contributed for development of organ reproduction yet, since there was no different in GSI. In order elucidate more on the taurine effect on reproduction stage of fresh water fishes, further investigation need to be conducted by using much older tilapia with weight ranging from $200-300$ grams. Determining of the FSH level or gonad's hormones should be undergone so that the onset time of reproductive status can be determined. As we had assumed that the taurine affected fresh water fishes juveniles for their muscle growth by improving the ability to absorb nutrient in the villi, this assumption also needs to be elucidated, one of which is by measuring the somatic-viceral index.

Over all, in order to generalize the function of taurine physiologically in fresh water fishes, some number species of fresh water fishes should be undergone for further investigation, such as in catfish or carpio.

\section{REFERENCES}

Bakker, A.J. and H.M. Berg. 2002. Effect of taurine on sarcoplasmic reticulum function and force in skinned fast-twitch skeletal muscle fibres of the rat. The Journal of Physiology, $538,185-194$.

Bianchi, L., M.A. Colivicchi, C. Ballini, M. Fattori, C. Venturi, M.G. Giovannini, J. Healy, K. F. Tipton, and L.D. Corte 2006. Taurine, Taurine Analogues, and Taurine Functions: Overview: Advances in Experimental Medicine and Biology

El-Sherbeny, A., H. Naggar, S. Miyauchi, M.S. Ola, D.M. Maddox, P.M. Martin, V. Ganapathy, and S.B. Smith 2004. Osmoregulation of Taurine Transporter Function and Expression in Retinal Pigment Epithelial, Ganglion, and Müller Cells. Investigative Ophthalmology and Visual Science. 45: 694-701. 
Brown-Peterson, N.J., R.M. Overstreet, and J.M. Lotz. 2001. Fish Bull: 99: 15-28

Goodman, C.A., D. Horvath, C. Stathis, T. Mori, K. Croft, R.M. Murphy and A. Hayes. 2009. Taurine supplementation increases skeletal muscle force production and protects muscle function during and after high frequency in vitro stimulation. J Appl Physiol (May 7, 2009). doi:10.1152/japplphysiol.00040.2009

Matsunari, H., H. Furuita, T. Yamamoto, S-K. Kim, Y. Sakakura, and T. Takeuchi. 2008. Effect of dietary taurinee and cystine on growth performance of juvenile red sea bream Pagrus major. Aquaculture 274: 142-147.

Mozaffari, M.S., and D. Schaffer. 2001. Taurine modulates arginine vasopressin-mediated regulation of renal function. Journal of cardiovascular pharmacology vol. 37, no 6, pp. $742-750$

Milante, J.D., and J.B. Lombardini. 2002. Taurine: evidence of physiological function in the retina. Nutr Neurosci. 5 (2): 75-90.

Salze, G., E. McLean, M.H. Schwarz, and S.R. Craig. 2008. Dietary mannan oligosaccharide enhances salinity tolerance and gut development of larval cobia. Aquaculture 274: 148152.

Schurr, A., M.T. Tseng, C.A. West, and B.M. Rigor. 1987. Taurine improves the recovery of neuronal function following cerebral hypoxia: An in vitro study Life Sciences. Vol. 40: Pp. 2059-2066.

van Gelder, N.M. 2005. Brain taurine content as a function of cerebral metabolic rate: Osmotic regulation of glucose derived water production. J. Neurochemical Research. Vo. 14 No. 6: $495-497$.

Widiastuti, E.L., and N. Nukmal. 2005. Studi Biologi pemanfaatan Osmolit Organik Taurinee pada Larva Kerapu Macan (Epinephelus fuscoguttatus, Forskal). J. Sains dan Teknologi Vol. 12 No. 2: 97 - 102.

Widiastuti, E.L., N. Nukmal, M. Kanedi, and S. Saputra. 2011. Taurine Effects on Growth and Gonad Maturation in Cobia (Rachycentron canadum). Proceeding of International Conference on Biological Science (ICBS-2011)- Gajah Mada University. 